\title{
XXX. Photographic phœnomena referring to the various actions of the red and yellow rays on daguerreotype plates when they have been affected by daylight
}

\section{A. Claudet Esq.}

To cite this article: A. Claudet Esq. (1848) XXX. Photographic phœnomena referring to the various actions of the red and yellow rays on daguerreotype plates when they have been affected by daylight, Philosophical Magazine Series 3, 32:214, 199-206, DOI: 10.1080/14786444808645963

To link to this article: http://dx.doi.org/10.1080/14786444808645963

$$
\text { 曲 Published online: } 30 \text { Apr } 2009 .
$$

Submit your article to this journal ए

\section{山 Article views: 2}

Q View related articles ¿ 
At all incidences, and in all azimnths within the shaded portions of the figure $\mathrm{ZAZD}, \mathrm{DCBC}$, the white-centred rings are seen. At all azimuths and incidences corresponding with the outlines of the curves $\mathrm{ZDZ}, \mathrm{DCBC}$, the rings disappear; and at all azimuths and incidences without the shaded portions of the figure, the black-centred rings are seen*.

St. Leonard's College, St. Andrews, April 8, 1841.

XXX. Photographic phanomena referring to the various Actions of the red and yellow Rays on Daguerreotype Plates when they have been affected by daylight. By A. Crauder, Esq.

To the Editors of the Philosophical Magazine and Journal. Gentlemen,

HAVING made on the 24th of October 1847, a communication to the Académie des Sciences of Paris similar to that I sent on the 10th of June to the Royal Society, On different Properties of Solar Radiation acting on Silver Plates coated with Iodine, or its compounds with Bromine or Chlorine, a discussion ensued, in which Messrs. Ed. Becquerel and Gaudin (see Comptes Rendus, Oct. 91 and Nov. 2) controverted the accuracy of some part of my experiments. I had stated that the red and yellow glasses had the property, as well as the pure red and yellow rays of the spectrum, of destroying the photogenic action produced by daylight on silver plates coated with iodine, or its compounds with bromine and chlorine; Messrs. Ed. Becquerel and Gaudin asserted that the red and yellow glasses had not the property of destroying, but of continuing the action commenced by daylight on the simply iodized plate.

As soon as I was apprised of the remarks made by Messrs. Becquerel and Gaudin, I repeated the experiments, and to my great surprise $I$ found that the destructive action of the red and yellow glasses did not appear, on this trial, to extend to the simply iodized, but only to the bromo-iodized plate. I lost no time in communicating to the Académie des Sciences the result of these experiments; and at the meeting of the $22 n d$ of November my letter stating the apparent contradiction was read.

This led me to continue the experiment, in order to examine the question more attentively, and fortunately enabled me to discover some new properties so interesting that I made

* No reference is made in these figures to the phænomena which are seen by using both polarized light and the analysing rhomb. 
a new memoir on the subject, at the same time trying to explain the anomaly existing between Messrs. Ed. Becquerel and Gaudin's experiments and my own.

As persons interested in these questions might only read my paper to the Royal Society, which you have inserted in full in the last Number of the Philosophical Magazine, I consider it my duty to publish immediately what has passed before the Académie des Sciences in reference to my communication; and I shall be much obliged if you will allow me a place in your pages for the insertion of the following translation of my new memoir to the Académie des Sciences, which has been read at the meeting of the 20th of December. (See Comptes Rendus.)

I have the honour to be, Gentlemen,
Your most obedient Servant,

A. Claudet.

I have again examined my former experiments, and I find some specimens which show that red and yellow glasses have destroyed the effect of the photogenic light on plates simply iodized. How can this fact be reconciled with Messrs. Ed. Becquerel and Gaudin's experiments, and those I had just made in consequence of these philosophers' observations? Had I made any mistake in the classification of my former specimens, or had I erred in my mode of operating? This might be, and I feared such was the case, as I just obtained quite different results. I then questioned my assistant, and he recollected well that we had repeatedly experimented upon plates simply iodized, and that we had then found that red and yellow glasses did destroy the action of daylight, as well on iodized plates as on those which had been submitted to the compound vapour of iodine and bromine.

I then recollected a curious fact mentioned by Dr. Draper of New York (see Phil. Mag., Feb. 1847, pages 89 and 90), which at the time of its publication I had found so inexplicable that I did not pay much attention to it, and which I had totally forgotten during the course of my experiments.

Dr. Draper said, "Such are the facts I observed, and they seem to have been reproduced by MM. Foucault and Fizeau; but there are also other's of a much more singular nature. In these Virginia specimens the same portecting action reappears beyond the violet.

"The only impressions in which I have ever seen this protecting action beyond the violet, are those made in Virginia in 1842; they were made in the month of July. Struck with 
this peculiarity, on my return to New York the following August I made many attempts to obtain similar specimens, but in no instance could the extra-violet protecting action be traced, though the analogous action of the red, orange, yellow, green and blue, was perfectly given. Supposing, therefore, that the difference must be due either to impurities in the iodine or to differences in the method of conducting the experiment, I tried it again and again in every possible way. To my surprise I soon found that the negative effect woas gradually disappearing; and on Sept. 29 it could no longer be traced, except at the highest part corresponding to the yellow and green rays. In December it had become still more imperfect, but on the 19th of the following March the red and orange rays had recovered their original protective power. It seemed, therefore, that in the early part of the year a protective action had made its appearance in the red ray, and about July extended over all the less refrangible regions, and as the year went on it had retreated upwards.

"Are there then periodic changes in the nature of the sun's light?" \&c.

From these experiments of Dr. Draper it would appear that, according to the months of the year in which we operate, the red and yellow rays either do or do not exercise a destructive action. It must be remarked that Dr. Draper mentions only iodized plates, that he always speaks of iodine alone, and that he never alludes to bromine or chlorine, which were hardly in use at the time of his experiments.

Dr. Draper adds (page 91), "I further found that when different rays are brought to act upon each other, the result does not alone depend upon their intrinsic differences, but also on their relative intensities. Thus the green and lower half of the blue rays, when of a certain intensity, protect the plate from the action of the daylight; but if of a less intensity, they aid the daylight.

"The red and orange rays, when of a certain intensity, increase the action of daylight on the plate; but if of a less intensity, they restrain it."

It would result from this last observation of Dr. Draper, that when the red and orange rays are not endowed with the destructive action, they, on the contrary, have the property of continuing or assisting the action of daylight.

Is it not then possible, that, like Dr. Draper, I may have made my first experiments on the iodized plate during the period when the red and yellow rays were endowed with their destructive action, and that Messrs. Becquerel and Gaudin may have made theirs when these rays had lost their destruc- 
tive and had acquired their continuing action, at a period corresponding to the present?

Having made my experiments with the greatest care, I seize with satisfaction this manner of explaining phænomena apparently contradictory. It would indeed be curious and interesting to find that neither myself nor the other experimenters are in error, and that we differ only as regards conditions and circumstances, which, without our knowledge, have exercised an influence upon our experiments. But there can be no doubt as regards the iodized plate, when it has been subsequently submitted to the vapour of bromine alone, or of bromine and chlorine united. I have operated with these substances during the various periods of the year, and I have invariably found that the red, orange, and yellow glasses destroy the action of daylight $*$.

This arises perhaps from the high degree of sensitiveness of all the coatings containing bromine. During the periods of the year when, by the intensity and purity of daylight, the simple iodide of silver has acquired the maximum of sensitiveness, it may be affected like the bromo-iodide, which, being about 100 times more sensitive, is always capable of receiving the destructive action of the less refrangible rays. Then it would appear that the destructive action of these rays require a highly sensitive coating to become manifest.

This manner of viewing the question is corroborated by a curious phænomenon, in other respects very interesting, and which I think has hitherto escaped the researches of photographers. I intended to treat this subject at some length in a separate paper, but I cannot do better than make use of this fact on the present occasion, and I shall therefore not defer its publication.

There exists a coating of iodide of silver which is twentyfive times more sensitive than the coating of Daguerre. Daguerre did not imagine that his process was susceptible of such a degree of sensitiveness. What an unexpected result at the time of his discovery! It is to be regretted that it escaped the inventor of the Daguerreotype, and that it did not precede

- I must here state, that considering the Daguerreotype plate as now exclusively prepared with bromine in addition to iodine, I have paid much more attention to this combination than to the original and now obsolete preparation of Daguerre containing only iodine; and I have had the opportunity of experimenting on plates prepared with iodine and bromine, and with iodine, bromine, and chlorine during a whole year, in all seasons; so that if there might exist any uncertainty as to the destructive effect of red and yellow glasses on silver plates simply iodized, there can be no doubt as to the permanency of the destructive effect on the bromo-iodized plate with or without chlorine, in every season and in all circumstances. 
the discovery of the accelerating action of bromine and chlorine, which we have found to be 100 times more sensitive*.

When the plate is prepared with this coating of iodine, the red and yellow glasses destroy the effect of daylight produced on that coating, in the same manner as when the iodized plate has been subsequently submitted to the vapour of bromine.

There are, then, certainly some cases when the red and yellow glasses are not endowed with the property of continuing the action commenced by daylight on the simply iodized plate, but when they are endowed with the property of destroying that action. This highly sensitive coating of iodine is obtained in the following manner:-

When a plate of silver is submitted to the vapour of iodine, it assumes at first a yellow tint, and afterwards becomes successively rose, red, violet, blue and blue-green; all these various tints constitute what I shall call the simple coating; they are all sensitive nearly in the same degree.

In continuing to iodize, a second coating is formed in a series of the same tints as the first. The plate becomes yellow a second time, and it passes successively through the rose, rel, violet, blue, and blue-green tints: this second coating is twenty-five times more sensitive than the first. But the most sensitive point is about the rose tint.

A third coating with the same tints can be obtained by a longer exposure to the vapour of iodine; but it is less sensitive than the second; the surface of the silver begins to be attacked by the strong action of the iodine; and after the washing with hyposulphite it appears milky, which injures the purity of the image.

If a silver plate be submitted to the vapour of iodine in such a manner as to give it gradually, by horizontal zones, all the tints of the first and second coatings, and in that state entirely affected by daylight, then exposed only on one vertical half during a few minutes under a red glass, so that the action of the red glass be exercised only on one half of each zone of the various tints of the two coatings, the mercurial vapour affects the surface in such a manner, as to show that the red glass has destroyed the action of daylight on the second coating of iodine, and has continued the same action on the first. The red glass has brought back the half of the more sensitive coating to the same degree of effect produced on the less sensitive, which has not received the action of the red glass. It

* I made the discovery of the accelerating property of chlorine, bromine and iodine combined in certain proportions in May 1841, and I communicated a paper on the subject to the Royal Society, which was read the 10 th of June following. 
has therefore destroyed the action of daylight on the more sensitive coating, and has continued the effect commenced on the less sensitive, to the same degree of intensity as the part of the more sensitive coating which has not received the action of red glass; so that each half of the plate has an effect perfectly equal and identical, in every point, to that of the other half, but in an inverted manner. A remarkable result is, that the horizontal zone, which is precisely in the middle of the plate, has the same intensity of photogenic effect in all its length. 'This proves that there has been neither destruction nor continuation on the space, where the coating by its thickness had the mean state of sensitiveness.

In putting aside the question of the influence of the various periods of the year on the destruction or continuation of the effect of daylight by the red and yellow rays, until we may have been able to verify the exactness of the facts mentioned by Dr. Draper, it is not possible to say in a general way that the red and yellow glasses are endowed with the property of continuing the effect of daylight on iodide of silver; for I have just proved that there are cases in which the contrary always takes place, according to the thickness of the coating of iodine.

Since the vapours of the atmosphere as well as the coloured glasses render the action of light negative, in absorbing certain rays and allowing only certain others to pass, it would not be surprising that, from the simultaneous action of the vapours of the atmosphere and of the coloured glasses, some contradictory effects might result; that when light has to pass through two different kinds of absorbing media, a certain effect could be produced; and that when the atmosphere is pure and free from all kinds of vapour, the absorption of coloured glass only might produce an effect of quite an opposite nature.

According to the position and density of the vapours of the atmosphere, all the points of the luminous space are not endowed with the same photogenic properties. So that in some circumstances a plate, first exposed to the blue light of the zenith, loses the property of receiving the mercurial vapour, if it be exposed a second time to the horizontal light of the south, when there exist some vapours, although not sufficiently dense to render the sun decidedly yellow. I have obtained specimens in which this curious result is manifest. One of them exhibits a negative image. This effect was produced by exposing a plate, first to the blue light of the zenith, and afterwards, covered with an engraving or a piece of black lace, to the light of the south.

The possible simultaneous existence of two antagonistic 
lights reflected from the atmosphere explains those anomalies which are so annoying to photographers; for example, those circumstances under which it seems impossible to obtain any image, whatever may be the length of exposure in the camera. This difficulty is imputed to the preparation of the plates, the state of the accelerating solutions, \&c.; and after all it only exists in the light. As much effect is often obtained in 30 seconds as in 120 seconds, for it is possible to have obtained a first effect which has been afterwards destroyed; and that must inevitably be the case if, during the latter part of the exposure in the camera obscura, any clouds or vapours have suddenly rendered the light of the sun yellow; in this case the object which had first reflected white light, becoming capable of reflecting only yellow light, this last must destroy the effect produced by the first.

If the object reflects at the same time blue light from the zenith and yellow light from the sonthern horizon, the two lights may be neutralized and destroy each other, so that no photogenic effect can be abtained. Sometimes, when the sky is cloudless, the space at the zenith is of a particularly deep blue colour; whereas the vapours produced by the heat of the sun make the sky appear slightly tinted with yellow, from the horizon to a certain height. In those circumstances all photographers must have observed that the operation in the camera obscura is excessively slow.

This may probably explain those dark specimens*, which were so weak in effect, obtained some years ago on the Alps during clear and cloudless weather, by an operator sent to Italy by $M$. Lerebours to take Daguerreotype views. $M$. Lerebours' operator was an experienced photngrapher, and he found, to his great surprise, that on the summit of the Alps he could not obtain any effect in less than five or six times what he considered to be the necessary exposure. He was surrounded with snow, the sun was shining in all its brilliancy, the sky was pure and cloudless, of a deep blue colour, whereas the horizon was without doubt slightly tinted yellow, on account of the vapours produced by the melting of the snow and ice of the glaciers.

Mr. Lerebours' operator was using at that time (in 1840) plates only iodized; and this fact would confirm the neutralization of the photogenic effect upon plates of iodide of silver, by the less refrangible rays acting simultaneously with white light, according to Dr. Draper's observations.

It would be interesting if $M$. Lerebours could state the

- I have one of these curious suecimens in my possession, for which I am indebted to M. Lerebours' kindness. 
period of the year in which his artist operated on the Alps; although it might be that from the high elevation of those regions the operator was precisely in those atmospheric conditions which exist on less elevated grounds during only certain months, on account of the density of the atmosphere that the sun's rays have to penetrate.

I shall not conclude this paper without expressing a wish that M. Ed. Becquerel, M. Gaudin, Messrs. Foucault and Fizean, as well as Dr. Draper, will continue their researches, and that we shall abstain from all discussion on this subject until we have been able to verify the facts under all possible circumstances. Time and only a few experiments will suffice to settle the question. We are all animated with the wish of arriving at the truth, and facts alone must now decide between us. Whatever may be the result, we all can individually congratulate ourselves on having contributed by our separate labours to the explanation of the phænomena of photography, and to the advancement of this new and interesting science.

XXXI. Observations on some remarkable Properties of Iodine, Phosphorus, Nitric Acid, \&c. By M. NiéPCE DE SAINTVICTOR*.

\section{On Iodine and its action.}

I BELIEVE that I first discovered a property of iodine which we should least expect it to possess, viz. that of being attracted by the black parts of an engraving, manuscript, \&c., leaving the white parts untouched. Thus, an engraving is submitted to the vapour of iodine for about five minutes at a temperature of from $60^{\circ}$ to $70^{\circ} \mathrm{F}$.; fifteen grammes of iodine are required for each square decimeter (a longer exposure is requisite at a lower temperature); this engraving is then laid upon paper " sized " with starch, care being taken to moisten it previously with water acidulated to $1^{\circ}$ with sulphuric acid. This is the only substance which as yet has been found to give the impressions any degree of permanency: however, they ultimately disappear on exposure to the air and light; but by pasting them beneath a plate of glass, they may be preserved for a very long time. The proofs just after having been pressed with a ball of linen exhibit remarkably distinct impressions, which on drying, however, become cloudy. But what is still more remarkable is, that several copies of the

* Translated from the Anna'es de Chimie et de Physique for January 1848, having been communicatel in two parts to the Académie des Sciences the 22nd of June 1846, and 11 th of January 1847. 